\title{
Ueber die nächsten Verwandten der Corticaria fulva Com. und einige Arten aus anderen Gruppen.
}

\author{
Ein coleopterologischer Bəitrag.
}

Von Edm. Reitter in Paskau (Mähren).

Eben als ich im Begriffe stand, eine nene Corticaria aus der fulva-Gruppe zu beschreiben, kommt mir B e l on's „Essai de Classification generale des Latrididae" in der Rev. d'Entom. Caen, 1897 pag. 105 et Folge zu, die ausgezeichnet, wie alle vorhergehenden Arbeiten über diese Familie dieses Autors, ich hier gebührend berücksichtigen kann.

In der fulva-Gruppe (III) ist in der neuen Monographie von Belo n die normanna Bris.= ciliata Motsch. (auch aus Madera), illaesa Mnnh., monticola Bris., pilosula Rosenh. uud fulva Com. enthalten.

Hiezu hat noch zu treten die C. transversicollis Motsch., welche aus Aegypten beschrieben, bisher zu der sehr nahestehenden fulva gezogen wurde. Sie unterscheidet sich durch queren Thorax ohne deutliche Basalgrube; manchmal ist sie flach vorhanden, und sind solche Exemplare offenbar die ebenfalls aus Aegypten beschriebene Pharaonis Motsch.; endlich 2 neue Specis aus dem Araxesthal und eine aus Turkestan.

$a^{\prime}$ Ein sehr kleines Schläfenzähnchen hinter den Augen und eine lange, rauhe Behaarung haben: C. normanna Bris., illaesa Mannh. und monticola Bris.;

a das Schläfenzähnchen fehlt ganz bei den nachtolgenden der fulva-Gruppe; die sich weiter theileu:

b. Halsschild kaum schmäler als die Flügeldecken, herzförmig, an den Seiten gerundet und in der Mitte, oder dicht vor der Mitte am breitesten;

$e^{\prime}$ Halsschild mit starkem Antebasalgrübchen; Flügeldecken mit abwechselnd rauhen, gehobenen Haarreihen. Kleine Art aus Spanien und Maroceo, fast von der Grösse der fulva $=C$. pilosula Rosenh.; 
c Halsschild mit flachem Antebasalgrübchen; Flügeldecken mit anliegender, feiner gelber Behaarung, die Zwischenräume kaum länger behaart als die Hauptreihen:

\section{Corticaria aequalis n. $\mathrm{sp}$.}

Grösser und breiter als pilosula, mehr parallel, oben flacher gewölbt und breiter, einfärbig braungelb, überall fein anliegend, auf den Decken dicht reihenweise gelb behaart. Fühler dünn und schlank, gelb, den Hinterrand des Halsschildes überragend, die Keule dünn und schlank, die Glieder fast etwas länger als breit, das letzte länglich oval. Kopf breiter als die halbe Thoraxbreite, dicht punktirt, mit grossen Augen. Halsschild quer, fast doppelt so breit als lang und fast so breit als die Flügeldecken, zur Basis etwas stärker verengt und hier fein gekerbt, die Seiten dicht vor der Mitte am breitesten, gelb bewimpert, Oberseite dicht und fein punktirt, Antebasalgrübchen seicht. Flügeldecken fast parallel, nahezu doppelt so lang als zusammen breit, mit feinen Punktreihen, die Zwischenreihen mit ganz gleichen Punktreihen, nur sind die Punkte weniger dicht gestellt, der Nahtstreif eingedrückt. Beine röthlichgelb. L on g. $2-3 \mathrm{~mm}$.

Unter den Arten der fulva-Gruppe durch die einförmige, anliegende Behaarung, durch breiten, parallelen und etwas abgeflachten Körper ausgezeichnet.

Ich erhielt sie in ziemlicher Anzahl aus dem Arax esthal bei Ordubad; 2 Exemplare aus Transkaspien (Askhabad).

$b$ Halsschild deutlich schmäler als die: Flügeldecken, mehr weniger herzförmig, weit vor der Mitte am breitesten;

d' Halsschild spärlich und seicht punktirt, und wenigstens die Zwischenräume auf den Flügeldecken mit langen geneigten Haarreihen :

\section{Cortiearia subpilosula n. sp.}

Der C. pilosula Rosenh. sehr ähnlich, von gleicher Grösse, Form und Färbung, aber der Thorax ist breiter, weit vor der Mitte am breitesten, nahezn herzförmig, seitlich lang bewimpert und sehr schwach gekerbt, mit 2-3 grösseren Zähnchen vor den Hinterecken, oben nur weitläufig und 
seicht punktirt, ebenso ist der Kopf fein und spärlich punktirt, die Fühler sind dünn, gelb, und ein wenig länger, die Keule schmäler, die vorletzten zwei Glieder ebenfalls nicht länger als breit. Flügeldecken bei gleicher Form und Sculptur ähnlich behaart, die abwechselnden regelmässigen Haarreihen sind doppelt länger und mehr gehoben. Von der C. fulva durch breiteren, weniger deutlich herzförmigen Thorax, der oben nur spärlich punktirt ist und durch die regelmässigeren, längeren Haarreihen auf den Zwischenräumen der Flügeldecken abweichend. L o $\mathrm{ng}$ g. kaum $2 \mathrm{~mm}$.

Araxesthal bei Ordubad, 2 Exemplare in meiner Sammlung.

\section{Corticaria illaesiformis n. sp.}

Braungelb, lang gelb und rauh behaart, die Behaarung gehoben und geneigt. Fühler gelb, dünn, den Hinterand des Halsschildes weit ïberragend, die Keule wenig breit, die 2 vorletzten Glieder so lang als breit, das Endglied etwas länger und breiter, eiförmig. Kopf spärlich punktirt, Augen gross. Halsschild sehr wenig schmäler als die Flügeldecken, viel breiter als lang, wie gewöhnlich hautartig reticulirt und spärlich, seicht punktirt, ảie Seiten herzförmig zur Basis verengt, weit vor der Mitte am breitesten, crenulirt, zur Basis fein gezähnelt, lang gelb bewimpert, Antebasalgrübchen nur angedeutet, seicht. Flügeldecken oval, mit mässig starken Punktreihen, die Zwischenpunktreihen ebenso kräftig, nur weniger dicht gestellt, die Haarstreifen lang, die abwechselnden länger und die einzelnen Haare nach hinten gekrümmt; Beine gelb. L o n g. : $2 \mathrm{~mm}$.

Von C. fulva durch den breiteren, aber spärlich punktirten Thorax und die sehr lange Behaarung des Körpers abweichend.

T u rkest a n : Taschkend. In meiner Sammlung.

$d$ Halsschild dicht und deutlich punktirt, Oberseite nur mässig lang behaart;

$e^{\prime}$ Halsschild wenig breiter als lang, stark herzförmig, mit kräftiger Antebasalgrube, die Haarreihen der Flügeldecken wenig rauh, fast anliegend, die abwechselnden wenig länger: C. fulva Com. 
e Halsschild stark quer, schwach herzförmig, mit schwacher und seichter (v. Pharaonis Motsch.), oder fast fehlender Antebasalgrube, die Fühler länger und dünner, die Flügeldecken ähnlich sculptirt und behaart: transversicollis Motsch., aus A e g y t e n.

Corticaria atricollis n. sp.

Mit $C$. longicornis Herbst (impressa Oliv.) nahe verwandt, von derselben Grösse, Körperform, Wölbung und ähnlicher Sculptur, aber schon durch die Färbung leicht zu unterscheiden. Glänzend, kastanienbraun, die Unterseite und der Thorax schwarz, die Fühlerbasis (Keule dunkel) und die Beine gelb. Fühler schlank, die Basis des Halsschildes überragend, die 2 vorletzten Glieder etwas länger als breit. Kopf sehr wenig schmäler als der Thorax, dicht punktirt, in seltenen Fällen auch schwarz, das Schläfenhöckerchen hinter den Augen sehr deutlich. Halsschild etwas breiter als lang, gewölbt, wenig gedrängt punktirt, mit kleinem, oft sehr flachem Basalgrübchen, die Seiten gerundet, zur Basis viel stärker verengt, fa s t $\mathrm{g}$ lat t $\mathrm{r}$ a n $\mathrm{dig}$. Flügeldecken rothbraun, glänzend, breiter als der Thorax, oval, mit vortretenden Schultern und ziemlich kräftigen Punktreihen, ohne Streifen, die Zwischenräume mit doppelt feinerer Punktreihe besetzt, Nahtstreif vertieft, Beine rothgelb, das Klauenglied dunkler. Beim $\sigma^{\pi}$ sind die Vorderschienen an der Spitze etwas nach innen gebogen. Oberseite nur selır spärlich, äusserst fein und kurz, gleichmässig behaart, fast kahl aussehend. L $0 \mathrm{ng}$. : $2-2 \cdot 2 \mathrm{~mm}$.

Quellgebiet des Irkut, von Hans Leder in einiger Zahl aus Laub gesiebt.

Ebenfalls zur Verwandtschaft der vorigen gehört :

Corticaria aphictoides n. sp.

Gross, kastanienbraun. Flügeldecken schwarz, Fühler und Beine gelbroth. Oberseite stark gewölbt, sehr spärlich, fein und kurz, gleichmässig gelblich behaart, glänzend. Fühler schlank, den Hinterrand des Halsschildes überragend, die Keule mässig abgesetzt, die 2 vorletzten Glieder so lang als breit, das Endglied länglich eiförmig. Kopf wenig schmäler als der Halsschild, fein und nicht dicht punktirt, zwischen den

Wiener Entomologische Zeitung, XVII. Jahrg., I. Heft (25, Januar 1898). 
Fühlern mit 2 seichten Eindrücken. Halsschild quer, um $1 / 3$ breiter als lang, wenig schmäler als die Flügeldecken, gewölbt, fein und dicht punktirt, mit länglichem. ziemlich tiefem Antebasalgrübchen, die Seiten gerundet, kaum gekerbt, fast glattrandig, vor der Mitte am breitesten, zur Basis etwas mehr verengt. Flügeldecken oval, gewölbt, am Ende gemeinschaftlich abgerundet, sehr dicht und ziemlich fein punktirt, die Punkte nur hie und da annähernd gereiht, nicht gestreift, nur ein Nahtstreif eingedrückt. L on g. : $2.5 \mathrm{~mm}$.

Nördli c lı e Mongo lei, bei Urga, von Hans Leder entdeckt. Meine Collection.

Mit C. linearis Payk. nahe verwandt ist:

Corticaria obscuripes n. sp.

Der verglichenen Art sehr ähnlich, von derselben Form und Grösse, aber schwarz, Kopf und Halsschild dunkel kastanienbraun, die gelbrothen Fühler mit dunkler Keule und dunklem Wurzelgliede, Beine braun, Schenkel schwarz, Tarsen braunroth. Oberseite äusserst fein und kurz, gleichmässig, fast staubartig, wenig dicht, hell behaart, glänzend. Fühler kurz, den Hinterrand des Halsschildes kaum erreichend, Glied 1 der Keule so lang als breit, das 2. quer, das Endglied kurz, eiförmig. Kopf wenig schmäler als der Thorax, dicht und fein punktirt. Halsschild merklich schmäler als die Flügeldecken, etwas breiter als lang, gerundet, vor der Mitte am breitesten, an den Seiten erloschen gekerbt, oben seicht und dicht punktirt mit grosser tiefer Antebasalgrube. Flügeldecken fast parallel, nahezu doppelt so lang als zusammen breit, an der Spitze gemeinschaftlich breit abgerundet, oben in Längsstreifen ziemlich kräftig punktirt, die Zwischenräume darum besonders vorn leicht gewölbt, und mit einer sehr feinen Punktreihe besetzt. L 0 n g. : $1.5-1.8 \mathrm{~mm}$.

Böhmen (Brandeis a. E.); von Hotrath Dr. K. Skalit z ky gesammelt. 


\section{$2 \mathrm{BHL}$ Biodiversity Heritage Library}

Reitter, Edmund. 1898. "Ueber die nächsten Verwandten der Corticaria fulva COM. und einige Arten aus anderen Gruppen." Wiener entomologische Zeitung 17, 28-32. https://doi.org/10.5962/bhl.part.3109.

View This Item Online: https://www.biodiversitylibrary.org/item/44201

DOI: https://doi.org/10.5962/bhl.part.3109

Permalink: https://www.biodiversitylibrary.org/partpdf/3109

\section{Holding Institution}

Smithsonian Libraries

\section{Sponsored by}

Smithsonian

\section{Copyright \& Reuse}

Copyright Status: NOT_IN_COPYRIGHT

This document was created from content at the Biodiversity Heritage Library, the world's largest open access digital library for biodiversity literature and archives. Visit BHL at https://www.biodiversitylibrary.org. 